\title{
Perceived size of off-size familiar objects under normal and degraded viewing conditions
}

SAMUEL S. FRANKLIN and NANCY L.
ERICKSON, Occidental College, 1600
Campus Road, Los Angeles, Calif. 90041

To examine the effect of familiar (assumed) size on perceived size Ss judged the heights of off-size chair under normal and degraded viewing conditions. Judgments of an enlarged chair regressed toward the familiar size and regression increased as visual information was degraded. Judgments of a reduced chair failed to show regression. apparently because that object was recognized as a nonrepresentative stimulus.

Transactional theorists (Ittelson, 1951) suggest that the perceived size of a familiar object is determined by assumptions associated with the retinal projection of the object. Gibson (1959), on the other hand, has noted the possibility of a psychophysical relation between optical stimulation and perceived size. According to a psychophysical analysis, size assumptions may be associated with an object but have no effect on size perception under normal viewing conditions. However, in an impoverished visual environment, where the psychophysical determinants of apparent size are unavailable, the $\mathrm{O}$ may rely on assumptions for his size judgments.

"Dark room" experiments, in which assumptions have been shown to affect the judged size and distance of a familiar object, do not provide unequivocal evidence for or against either theory since both predict an assumptive effect under such impoverished conditions. Recent investigations have attempted to pit the theories by obtaining judgments under normal viewing conditions. Slack (1956) obtained size estimations of wooden stakes and especially constructed off-size chairs on an outdoor field. He proposed that if assumptions influence size perception, judgments of the chairs would regress toward the familiar size. In accord with predictions, the reduced chair appeared slightly larger and the enlarged chair appeared slightly smaller than their respective control objects. Fillenbaum, Shiffman, \& Butcher (1965), however, failed to replicate Slack's findings. Shiffman (1967) presented off-size familiar objects under "informative" and reduced conditions and found regression only in the latter situation. Shiffman concluded that the effect of assumptions depends upon the visual information available.
The purpose of the present investigation was to further examine this hypothesis by obtaining judgments of off-size familiar objects under different conditions of viewing.

\section{METHOD}

Forty volunteers from introductory psychology classes served as Ss. All Ss were naive as to the purpose of the experiment which was conducted on an unmarked football field. Twenty Ss judged the size of two especially constructed chairs and two unfamiliar control objects under unrestricted daylight conditions. Twenty additional Ss judged the same stimuli on the field at night when distance information was present but degraded. A 100-W reflector floodlight, placed $3 \mathrm{ft}$ in front and $5 \mathrm{ft}$ to the right, illuminated the objects at night.

The chairs were off-size replicas of a conventional kitchen-type chair with metal frame and padded seat and back. They were accurately proportioned but reduced or enlarged $25 \%$ of their standard size (31 in.). The control objects were abstract forms of the same heights as the chairs (38\% in. and $23 \frac{1}{4}$ in.), were constructed from the same materials, and were of approximately equal complexity.

The Ss were instructed to " . . judge the size, that is, the heights, of the various objects as you would judge the heights of things every day." The objects were presented one at a time and $S$ judged the size of each by instructing $E$ to adjust a tape measure (markings not in view) to the same height (cf. Slack, 1956; Fillenbaum et al, 1965). Two judgments of each object at each of three distances, 10, 20, and $40 \mathrm{yd}$, were obtained. The order of objects and distances was randomized between Ss. Prior to presenting the chairs and control objects, $S$ received four practice trials on a 30 -in. stake placed at $15,25,35$, and $45 \mathrm{yd}$.

\section{RESULTS AND DISCUSSION}

Judgments of the large and small objects were treated in separate 2 by 3 by 2 analyses of variance as two replications of a single experiment. In both analyses main effects of distance $(p<.01)$ and Illumination by Distance interactions $(p<.01)$ were obtained. Individual tests of the interactions indicated that the overestimation present in all judgments (see Table 1) increased with distance during the day but not at night. With the exception of the small chair at $40 \mathrm{yd}$ the judged size of both familiar and unfamiliar objects remained stable over distance in the degraded viewing condition.

The findings suggest that: (1) overconstancy (the tendency for size judgments to increase with increasing distance) was mediated by information within an enriched visual field rather than by a judgmental process which occurs in the absence of adequate visual information (see Wohlwill, 1963); (2) since familiar as well as unfamiliar stimuli exhibited overconstancy it must be concluded that the perceived size of a known object is not determined solely by the interaction of its retinal projection and assumptions.

\section{Large Objects}

As predicted by transactional theory the large chair was underestimated relative to its control object. The mean judged size of the chair and abstract forms were $42.81 \mathrm{in}$. and $44.70 \mathrm{in}$., respectively. A main effect of objects $(F=56.8, \mathrm{df}=1 / 38, \mathrm{p}<.01)$ indicated these means to be significantly different. Underestimation of the chair relative to the abstract form was greater at night $(\mathrm{p}<.01)$ than during the day $(\mathrm{p}<.05)$ as indicated by a significant Illumination by Objects interaction $(F=15.1, \mathrm{df}=1 / 38, \mathrm{p}<.01)$. Individual tests of this interaction also revealed that while estimates of chair size were smaller at night than during the day $(\mathrm{p}<.01)$, the judged size of the abstract form did not differ between illumination conditions. Apparently both conditions provided sufficient visual information to make a reliable size judgment of the control object. To estimate the size of the familiar object $S$ could rely upon this information and/or utilize familiar size assumptions. The data suggest that assumptions were employed regardless of viewing conditions but that their contribution to apparent size increased when visual information was degraded.

As the distance of an object is increased

Table I

Mean Apparent Heights (in.)

\begin{tabular}{|c|c|c|c|c|c|c|}
\hline & $10 \mathrm{yds}$ & $\begin{array}{c}\text { Abstract } \\
20 \mathrm{yds}\end{array}$ & $40 \mathrm{yds}$ & $10 \mathrm{yds}$ & $\begin{array}{l}\text { Chair } \\
20 \mathrm{yds}\end{array}$ & $40 \mathrm{yds}$ \\
\hline \multicolumn{7}{|l|}{ Large Objects } \\
\hline $\begin{array}{l}\text { Day } \\
\text { Night }\end{array}$ & $\begin{array}{l}42.81 \\
44.17\end{array}$ & $\begin{array}{l}44.56 \\
45.16\end{array}$ & $\begin{array}{l}46.17 \\
45.30\end{array}$ & $\begin{array}{l}42.09 \\
42.25\end{array}$ & $\begin{array}{l}43.78 \\
42.11\end{array}$ & $\begin{array}{l}44.91 \\
41.71\end{array}$ \\
\hline $\begin{array}{l}\text { Small Objects } \\
\text { Day } \\
\text { Night }\end{array}$ & $\begin{array}{l}27.72 \\
27.95\end{array}$ & $\begin{array}{l}29.48 \\
28.55\end{array}$ & $\begin{array}{l}32.18 \\
28.08\end{array}$ & $\begin{array}{l}26.84 \\
27.01\end{array}$ & $\begin{array}{l}29.99 \\
26.80 \\
\end{array}$ & $\begin{array}{r}30.64 \\
28.50 \\
\end{array}$ \\
\hline
\end{tabular}


some of the visual information that mediates apparent size should be reduced. Under these conditions assumptive effects might be expected to increase. The Objects by Distance interaction failed to reach the .05 level $(F=3.0, d f=2 / 76 ;$ required $F=3.12)$, but the data suggest that underestimation of the chair relative to the control object did tend to increase with increasing distance. The abstract-chair mean differences were $1.32,1.92$, and 2.42 in. for the 10-, 20-, and 40 -yd distances, respectively.

\section{Small Objects}

The analysis for the small stimuli revealed a significant main effect of objects $(F=4.8$, $\mathrm{df}=1 / 38, \mathrm{p}<.05)$; however, contrary to transactional predictions, the small chair was underestimated relative to the control object. Neither the Illumination by Objects nor the Objects by Distance interactions were significant. The interaction of Illumination by Objects by Distance was significant $(F=26.7, \mathrm{df}=2 / 76, \mathrm{p}<.01)$, and individual tests suggested that it was probably due to a significant increase in judged chair size at the 40-yd night condition. The relatively large estimate of the chair in this most degraded condition appears to be the only evidence for the effect of assumptions in the small-object data.

The disparate findings of the large and small objects suggested to us that the two off-size chairs may have differed in some unexpected but important way. Fillenbaum et al (1965) proposed that if a familiar object is grossly off-size, an $O$ might recognize a nonrepresentative stimulus and avoid using familiar size assumptions. This hypothesis was offered as a possible explanation for their failure to replicate the results of Slack's investigation. Both the reduced and enlarged chairs of the present experiment were $25 \%$ off-size. Because rather strong evidence for an effect of familiar size was obtained with one chair and not with the other, a supplementary study was conducted to determine whether the two objects appeared equally distorted in size.

Twelve Ss judged either the large or small chair from a distance of $20 \mathrm{ft}$ on a large, flat lawn under unrestricted daylight conditions. First, $S$ reported whether the chair appeared normal size, smaller than normal, or larger than normal. If an off-size judgment was obtained, $S$ estimated the percentage of enlargement or reduction from normal size. All 12 Ss judged the reduced chair to be undersize, and 11 of $12 \mathrm{Ss}$ judged the enlarged chair to be oversize. The mean off-size estimates were $39.5 \%(\mathrm{SD}=16.5)$ and $21.1 \%(\mathrm{SD}=11.1)$ for the reduced and enlarged chairs, respectively $(\mathrm{t}=3.12$, $\mathrm{df}=22, \mathrm{p}<.01$, two-tail). Although we have been unable to determine why the apparent distortion of the small chair was almost twice that of the large chair, the fact that it was recognized as grossly off-size may have inhibited the influence of familiar size assumptions.

Familiar size assumptions were found to influence the apparent size of the large chair despite the availability of visual information about its actual size. This finding is not in accord with Gibson's psychophysical theory but speaks for the transactional analysis of perception. The results of the present investigation suggest, however, that the apparent size of a familiar object is determined by both visual and assumptive information, and that their relative effects depend upon the viewing conditions and upon the representativeness of the object.
REFERENCES

FILLENBAUM, S., SHIFIMAN, H. R., \& BUTCHER, J. Perception of off-size versions of a familiar object under conditions of rich information. Journal of Experimental Psy chology, 1965, 69, 298-303.

GIBSON, J. J. Perception as a function of stimulation. In S. Koch (Ed.), Psvchology: A study of a science. New York: McGraw-Hill, 1959. P. 178.

ITTELSON, W. H. Size as a cue to distance: Static localization. American Journal of Psychology, $1951,64,54-67$.

SHIFFMAN, H. R. Size-estimation of familiar objects under informative and reduced conditions of viewing. American Journal of Psychology, 1967, 80, 229-235.

SLACK, C. W. Familiar size as a cue to size in the presence of conflicting cues. Journal of Experimental Psychology, 1956, 52, 194-198.

WOHLWILL, J. F. Overconstancy in distance perception as a function of texture of the stimulus ficld and other variables. Perceptual \& Motor Skills, 1963, 17, 831-846.

\section{On Rock's one-trial learning controversy'}

ROBERT L. BRECKENRIDGE, Texas Christian University, Fort Worth, Tex. 76129, and EARL W. KOOKER, North Texas State University, Denton, Tex. 76203

One group of $S s$ (DOC) learned a PA list by a method requiring one-trial learning. Unlearned items were replaced by new pairs on every trial. Another group (C1) learned the PA list by the repetition method, retaining unlearned items. A third group (C2) learned a list by the same repetition method, but the list learned by a given $S$ in this group was composed of items finally learned by an $S$ in the one-trial learning group. In all groups, learned pairs were removed from the list after having been correctly associated once. An analysis of the number of errors to one correct trial found that $C 1$ differed from neither $C 2$ nor $D O C$, but $C 2$ and DOC differed significantly. Analysis of the number of associations correctly recalled 1 min after the list had been learned, however, found significant differences between DOC and both repetition groups. This was interpreted as support of an incremental hypothesis.

In a series of studies of paired-associate (PA) learning, Rock (1957; Rock \& Heimer, 1959; Rock \& Steinfield, 1963) reported data which were interpreted as supporting a one-trial learning hypothesis as opposed to an incremental learning hypothesis. In Rock's paradigm, the experimental group learned a list of PA items. After each trial, unlearned pairs were replaced by new and unfamiliar pairs. No significant difference was found between the number of trials required for the experimental group and the number required by $\mathrm{Ss}$ who saw the same pairs on every trial (repetition method). Rock proposed that an incremental hypothesis would predict differences between these two groups in favor of the repetition group, while an all-or-none, or a one-trial hypothesis, would predict no differences. These results were subsequently supported by Clark, Lansford, \& Dallenbach (1960).

Underwood, Rehula, \& Keppel (1962) and Postman (1962) replicated Rock's paradigm, but added a second control group to determine whether or not the insertion of new pairs (and the dropping of unlearned or missed pairs) for Rock's one-trial group facilitated the performance of this group. They suggested that the one-trial group could have been learning a set of pairs that were easier than those pairs learned by the control group. This could occur since difficult pairs might be missed, deleted from the list and subsequently replaced by pairs more representative of the general pool which, therefore, would be easier than the dropped pairs. Such item selection would effectively result in easier lists. The control group 